\title{
Inverted Apical CD24 and Weak EZH2 Expressions Are Phenotypic Characteristics of Pure Invasive Micropapillary Carcinoma of the Breast
}

\author{
Nadège Gruel $^{1,2}$, Aurélie Cédenot ${ }^{3}$, Marion Richardson ${ }^{3}$, Paul Fréneaux ${ }^{3}$, Jaydutt Bhalshankar ${ }^{2}$, \\ Thierry Dubois ${ }^{1}$, Xavier Sastre-Garau ${ }^{3}$, Olivier Delattre ${ }^{2}$, Anne Vincent-Salomon ${ }^{2,3 *}$
}

${ }^{1}$ Translational Research Department, Institut Curie, Paris, France; ${ }^{2}$ INSERM Unit 830, Institut Curie, Paris, France; ${ }^{3}$ Department of Tumor Biology, Institut Curie, Paris, France.

Email: *anne.salomon@curie.net

Received November $28^{\text {th }}, 2012$; revised December $20^{\text {th }}, 2012$; accepted January $19^{\text {th }}, 2013$

Copyright (C) 2013 Nadège Gruel et al. This is an open access article distributed under the Creative Commons Attribution License, which permits unrestricted use, distribution, and reproduction in any medium, provided the original work is properly cited.

\begin{abstract}
Invasive micropapillary carcinomas (IMPC) of the breast account for less than $2 \%$ of all breast cancers and have been recently described as luminal B carcinomas. CD24, CD44, ALDH1 and EZH2 are commonly used as stem-cell markers that display differential expression as a function of stage and molecular type, but their pattern of expression according to this rare histological type remains poorly defined and unknown for EZH2. We assessed expression of these markers in a series of 28 micropapillary breast carcinomas and compared the results with those obtained in a series of luminal A (27 cases) and B (34 cases) invasive carcinomas of no special type (IC-NST). CD24 and CD44 were expressed in most cases. However, CD24 was expressed at the inverted apical membrane in $85 \%$ of invasive micropapillary carcinoma and at the apical pole of gland-forming cells in $45 \%$ of luminal A ( $p$-val $\left.=6.8 \times 10^{-4}\right)$ and $13 \%$ of luminal B cases $\left(p\right.$-val $\left.=1.1 \times 10^{-7}\right)$. ALDH1 was expressed in the stroma in most tumors, but in only $25 \%, 11 \%$ and $15 \%$ in epithelial cells of IMPC, luminal A and B IC-NST, respectively. Nuclear expression of EZH2 was not observed in luminal A tumors, and was detected in 35\% (12/34) of luminal B carcinomas $\left(p\right.$-val $\left.=6.1 \times 10^{-3}\right)$ and only $4 \%(1 / 28)$ of invasive micropapillary carcinomas. This series shows that invasive micropapillary carcinomas harbor a CD24-positive inverted apical pole associated with weak EZH2 expression, phenotypical characteristics that distinguish this entity from other luminal carcinomas.
\end{abstract}

Keywords: CD44; CD24; ALDH1; EZH2; Invasive Micropapillary Breast Carcinoma

\section{Introduction}

Breast carcinoma comprises many different entities characterized by specific molecular alterations. Tumor gene expression analyses have identified major molecular subtypes: luminal A, luminal B, HER2 $2^{+}$, basal-like and normal breast-like groups $[1,2]$ and, more recently, the apocrine and claudin-low groups $[3,4]$.

Breast cancer-initiating cells have been defined as cells with properties responsible for tumor initiation, potentially driving tumor growth and metastasis, although these statements are still a subject of debate $[5,6]$. Xenotransplant assays in non-obese diabetic severe combined immunodeficiency (NOD/SCID) mice [7] have identified $\operatorname{lin}^{-} / \mathrm{CD}_{4} 4^{+} / \mathrm{CD} 24^{-}$cells as candidate breast cancer-initiating cells (BrCICs). Additional markers, such as ALDH1

"Corresponding author.
[8] alone or in conjunction with the $\mathrm{CD} 44^{+} / \mathrm{CD} 24^{-}$phenotype, have also been proposed as putative markers of BrCICs.

EZH2 belongs to the Polycomb group of proteins, which are involved in chromatin-modifying complexes, and stem cell self-renewal, a property of BrCICs, and are deregulated in cancer $[9,10]$. Although rarely chosen as a stem cell marker, EZH2 expression is poorly known in specific histological subtypes and is therefore assessed.

The identification in clinical practice of these BrCICs should help to understand chemo-radiotherapy resistance as stem cells and BrCICs have been shown to be more resistant to treatment than more differentiated cells [11]. In that context, the expression of CD44, CD24, and ALDH1 have been accurately assessed on tissue sections, by immunohistochemistry. The expression patterns of these 
markers $\mathrm{CD} 44^{+} / \mathrm{CD} 24^{-}$and ALDH1 differed between tumor molecular subtypes and stages. Basal-like carcinomas were recently shown to be enriched in $\mathrm{CD}_{4} 4^{+}$/ $\mathrm{CD} 24^{-}$cells, whereas HER2 ${ }^{+}$tumors have a predominantly $\mathrm{CD} 24^{+}$phenotype $[12,13]$. CD44 expression is weaker in invasive tumors than in in situ tumors, such as those of the luminal A subtype, in particular [14]. ALDH1 ${ }^{+}$ cells seem to be more frequent in basal-like and HER2 ${ }^{+}$ tumors than in luminal tumors. $\mathrm{CD} 44^{+} / \mathrm{CD} 24^{-} / \mathrm{ALDH}^{+}$ cells are associated with axillary lymph node-positive status and correlated with a poorer patient outcome [15]. EZH2 expression has been associated with poorly differentiated tumors and poor prognosis [16]. Histological types have a clinical impact in treatment decisions, some being associated with good, others with aggressive outcomes [17]. Furthermore, the knowledge of their specificities contributes to their better characterisation.

Few studies have yet addressed the specific pattern of this combination of four markers expression in histological rare sub-types [18]. Invasive micropapillary carcinoma (IMPC) is a histological type of tumor accounting for less than $2 \%$ of all breast cancers. IMPC consists of tumor cells organized into nests presenting an insideout pattern of MUC-1 labelling, separated from the extracellular matrix by a clear space. More than $60 \%$ of IMPC display lympho-vascular invasion and axillary lymph node metastasis and therefore are assumed to constitute an aggressive entity [19]. This histological type has been recognized as part of the luminal spectrum of breast carcinomas [20].

Though, we investigated the expression of CD44, CD24, ALDH1 and EZH2 in a series of 28 IMPC from a single institution. As IMPC have recently been proposed to belong to the group of luminal carcinomas [20] and more specifically to luminal B carcinomas [21], we compared the expression of these markers with that observed in a consecutive series of 27 luminal A and 34 luminal B carcinomas.

Most of the IMPC harbored a specific pattern of CD24 expression different from that of the other luminal tumors analyzed and demonstrated a rare nuclear expression of EZH2.

\section{Materials and Methods}

\subsection{Patients and Tumors}

We retrospectively selected 89 cases of invasive breast cancer-28 IMPC, 27 luminal A and 34 luminal B invasive carcinomas of no special type (IC-NST) - on the basis of the availability of clinical data, paraffin blocks and clinical follow-up information from our tumor bank. Initial treatment was surgery in all selected cases. These cases were reviewed by two experienced breast pathologists (AVS and PF), according to the World Health Organization (WHO) classification criteria. IMPC cases were recognized on the basis of inside-out MUC-1 staining at the inverted apical pole. IC-NST were defined as luminal $\mathrm{A}$ if grade $\mathrm{I}$ or II and $\mathrm{ER}^{+} / \mathrm{PR}^{+} / \mathrm{ERBB}^{-}$, and as luminal $\mathrm{B}$ if $\mathrm{ER}^{+}$and grade III or ERBB2 (3+) [22]. Experiments were performed in accordance with Bioethics Law No. 2004-800 and the Ethics Charter of the French National Institute of Cancer (INCa) and after approval of the ethics committee of our institution.

\subsection{Immunohistochemical Analyses}

Tissue microarrays (TMA) were constructed with three representative cores (1 $\mathrm{mm}$ in diameter) of each tumor and one core of normal surrounding breast tissue for each case. Four $\mu \mathrm{m}$ thick sections were obtained from formalin-fixed, paraffin-embedded tissues for TMAs. These sections were cut, dried, deparaffinised and rehydrated according to standard procedures. All sections were subjected to heat-induced antigen retrieval in citrate buffer (pH 6.1). Estrogen receptor (ER, clone 6F11, 1:200, Novocastra), progesterone receptor (PR, clone 1A6, 1:200, Novocastra), ERBB2 (clone CB11, 1:1,000, Novocastra), CD44 (Thermo Scientific, clone 156/3C11, 1:100), CD24 (Thermo Scientific, clone SN3b, 1:100), ALDH1 (BD Transduction Laboratories, clone 44/ALDH, 1:200) and EZH2 (Novocastra, clone 6A10, 1:100) expressions were then evaluated. Internal and external positive and negative controls were included for each antibody. Staining was detected with the Vectastain Elite ABC peroxidase mouse IgG kit (Vector Burlingame, CA), with diaminobenzidine (Dako A/S, Glostrup, Denmark) as chromogen. Cases were considered positive for ER and PR when $10 \%$ of cells were positive for these markers [23], and the ASCO cut-off was used to determine whether cases were positive for ERBB2 [24].

\subsection{Immunohistochemical Scoring for CD44, CD24, ALDH1 and EZH2}

For CD24 and CD44 the most frequently used cut-off of $10 \%$ of positive cells was chosen $[14,25,26]$. For ALDH1, the reported cut-offs in literature ranged from one positive cell to $10 \%$ of positive cells $[14,15,27]$. One positive cell cut-off was chosen. For EZH2, we determined our interpretation method according to Kleer et al. [16]: a case was considered as negative when no staining was observed and positive when any cell was stained with any intensity of staining. Cellular and subcellular localization in normal breast tissue and in carcinomatous cells was taken into account. 


\subsection{Survival Analyses}

The homogeneity between groups of different tumor types was evaluated by the Pearson Chi-square test. Statistical analyses of survival were carried out with MedCalc $^{\circledR}$ software. Cumulative overall survival was calculated by the Kaplan-Meier method, and the log-rank test was used to analyse differences in survival times. A $p$ value $\leq 0.05$ was considered significant.

\section{Results}

\subsection{Patient and Tumor Characteristics}

A set of 28 IMPC, 27 luminal A and 34 luminal B ICNST was analyzed. The median age of the patients, not statistically different among the three groups (Table 1), was 57.5 years (range, $33-81$ years) for IMPC, 51.9 years (range, 34 - 66 years) for luminal A tumors and 54.7 years (range, 28 - 80 years) for luminal B tumors. All patients were treated according to stage, prognostic and predictive parameters and established protocols: mastectomy (23/89 patients, $26 \%$ of cases) or conservative surgery (66/89 patients, $74 \%$ of cases) followed by radiation therapy (79/83 patients, $95 \%$ of cases). Adjuvant therapies included chemotherapy for 14 of the 28 IMPC $(50 \%), 10$ of the 27 luminal A tumors (37\%) and 28 of the 34 luminal B tumors $(82 \%)$, and endocrine therapy for 23 of the 28 IMPC (82\%), 24 of the 27 luminal A tumors $(89 \%)$ and 30 of the $34(88 \%)$ luminal B tumors. Patients with tumors displaying ERBB2 amplification received trastuzumab in an adjuvant setting, in line with protocols established after December 2005, for 2 of the 9 IMPC (22\%) and 15 of the 33 luminal B tumor (45\%) patients concerned. The clinical and pathological characteristics of the tumor and the mode of treatment are indicated in Table 1. Most of the IMPC were grade II and III, $\mathrm{ER}^{+}(26 /$ 28 patients, $93 \%$ of cases) and $\mathrm{PR}^{+}(23 / 28$ patients, $82 \%$ of cases), and $32 \%$ of cases ( $9 / 28$ patients) were ERBB2 $3+$. The proportion of tumors with positive nodal status was significantly higher for IMPC ( $73 \%$ of cases) than for luminal A tumors $\left(37 \%\right.$; $p$-val $\left.=1.8 \times 10^{-2}\right)$, but no significant difference was observed between IMPC and luminal B tumors $(61 \%$; $p$-val $=\mathrm{ns})$. The proportion of cases presenting lympho-vascular invasion was significantly higher for IMPC than for either luminal A or luminal B tumors $\left(86 \% ; 37 \% p\right.$-val $=5.8 \times 10^{-4}$ and $47 \%, p$ $\left.\mathrm{val}=3.7 \times 10^{-3}\right)$.

\subsection{CD44, CD24, ALDH1 and EZH2 Expression}

The expression of the CD44, CD24, ALDH1 and EZH2 markers was analyzed, as these markers have been shown to be associated with either more differentiated luminal epithelial (CD24) or stem cell-like (CD44, ALDH1, EZH2) characteristics (Figure 1). As reported by Park

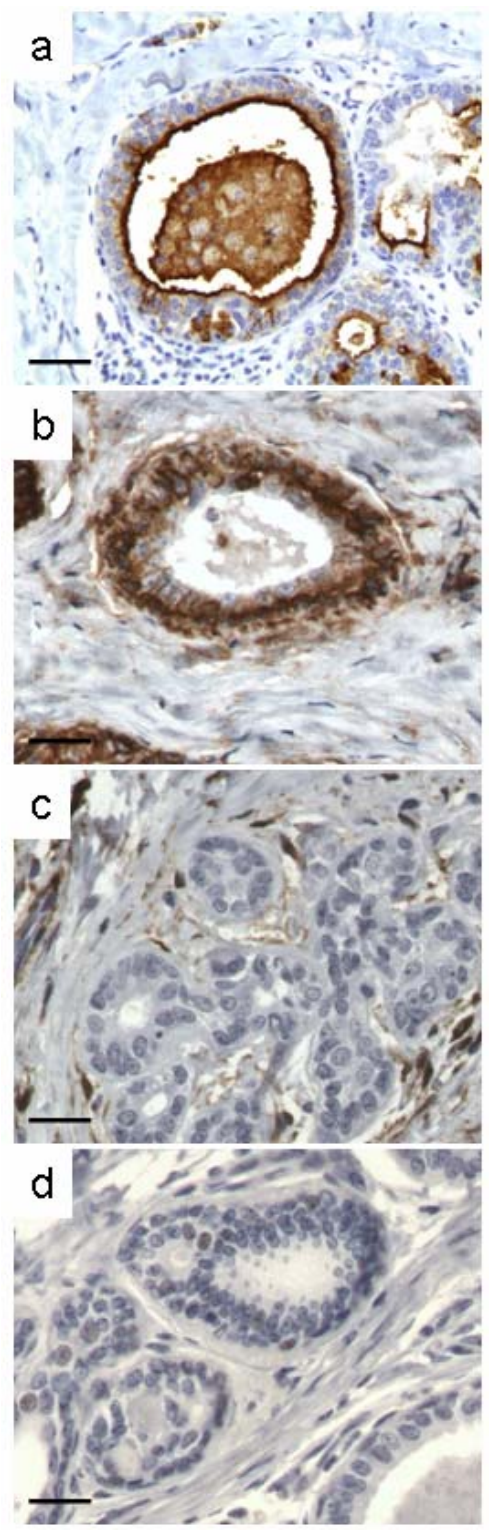

Figure 1. Examples of immunohistochemical analysis of CD24, CD44, ALDH1 and EZH2 expression in normal lobules. (a) CD24; (b) CD44; (c) ALDH1; (d) EZH2. Scale: 20 $\mu \mathrm{m}$.

and co-workers [14] for normal breast tissue surrounding tumors, CD24 expression was observed on the apical membrane of luminal cells (Figure 1(a)) and CD44 was localized at the cell membrane of myoepithelial cells and some luminal epithelial cells in lobules (Figure 1(b)). No ALDH1 expression was detected in normal duct epithetlium (Figure 1(c)), but staining was observed in the connective tissue surrounding normal acini. Nuclear expression of EZH2 was rarely observed in normal acini (Figure 1(d)).

The expression of these markers was further investigated in tumor cells (Figure $\mathbf{2}$ and Table 2). CD24 label- 
Table 1. Clinical and pathological characteristics of the 28 IMPC and 61 luminal A and B IC-NST cases. Legends: 1) $p$-val: IMPC vs luminal A IC-NST ; 2) p-val IMPC vs luminal B IC-NST; 3) p-val luminal A IC-NST vs luminal B IC-NST.

\begin{tabular}{|c|c|c|c|c|c|c|}
\hline & IMPC & Lum A & Lum B & 1 & 2 & 3 \\
\hline & & $\mathrm{n}(\%)$ & & & $p$-value & \\
\hline Number of patients & 28 & 27 & 34 & & & \\
\hline Median follow-up, yrs [range] & $6.9[3.9-10]$ & $3.2[0.1-8.9]$ & $3.7[0.8-6.9]$ & & & \\
\hline Median age, years & 57.5 & 51.9 & 54.7 & & & \\
\hline$<50$ & $9(32)$ & $11(41)$ & $12(35)$ & $\mathrm{ns}$ & $\mathrm{ns}$ & ns \\
\hline$\geq 50$ & $19(68)$ & $16(59)$ & $22(65)$ & & & \\
\hline \multicolumn{7}{|l|}{ Tumor size, cm } \\
\hline$<2$ & $17(60)$ & $20(74)$ & $11(32)$ & & & \\
\hline 2 to 5 & $10(36)$ & $7(26)$ & $19(56)$ & ns & ns & $3.1 \times 10^{-3}$ \\
\hline$>5$ & $1(4)$ & $0(0)$ & $4(12)$ & & & \\
\hline \multicolumn{7}{|l|}{ Grade } \\
\hline I & $1(4)$ & $26(96)$ & $0(0)$ & & & \\
\hline II & $16(57)$ & $1(4)$ & $0(0)$ & $5.1 \times 10^{-11}$ & $6.7 \times 10^{-7}$ & $5.6 \times 10^{-14}$ \\
\hline III & $11(39)$ & $0(0)$ & $34(100)$ & & & \\
\hline \multicolumn{7}{|l|}{ Nodal status } \\
\hline Positive & $19(73)$ & $10(37)$ & $20(61)$ & $1.8 \times 10^{-2}$ & ns & ns \\
\hline Negative & $7(27)$ & $17(63)$ & $13(39)$ & & & \\
\hline Not specified & 2 & 0 & 1 & & & \\
\hline \multicolumn{7}{|l|}{ Lympho-vascular invasion } \\
\hline Positive & $24(86)$ & $10(37)$ & $16(47)$ & $5.8 \times 10^{-4}$ & $3.7 \times 10^{-3}$ & $\mathrm{~ns}$ \\
\hline Negative & $4(14)$ & $17(63)$ & $18(53)$ & & & \\
\hline Conservative surgery & $17(61)$ & $26(96)$ & $23(67)$ & $4.1 \times 10^{-3}$ & $\mathrm{~ns}$ & $1.3 \times 10^{-2}$ \\
\hline \multicolumn{7}{|l|}{ Adjuvant therapies } \\
\hline Cytotoxic chemotherapy & $14(50)$ & $10(27)$ & $28(82)$ & $\mathrm{ns}$ & $1.4 \times 10^{-2}$ & $7.7 \times 10^{-4}$ \\
\hline Endocrine therapy & $23(82)$ & $24(89)$ & $30(88)$ & $\mathrm{ns}$ & ns & ns \\
\hline \multicolumn{7}{|l|}{ ER } \\
\hline Positive & $26(93)$ & $27(100)$ & $34(100)$ & $\mathrm{ns}$ & ns & $\mathrm{ns}$ \\
\hline Negative & $2(7)$ & $0(0)$ & $0(0)$ & & & \\
\hline \multicolumn{7}{|l|}{ PR } \\
\hline Positive & $23(82)$ & $27(100)$ & $15(45)$ & $\mathrm{ns}$ & $7.3 \times 10^{-3}$ & $1.6 \times 10^{-5}$ \\
\hline Negative & $5(18)$ & $0(0)$ & $18(55)$ & & & \\
\hline Not specified & 0 & 0 & 1 & & & \\
\hline \multicolumn{7}{|l|}{ ERBB2 } \\
\hline Positive & $9(32)$ & $0(0)$ & $33(97)$ & $4.2 \times 10^{-3}$ & $2.3 \times 10^{-7}$ & $2.9 \times 10^{-13}$ \\
\hline Negative & $19(68)$ & $27(100)$ & $1(3)$ & & & \\
\hline
\end{tabular}




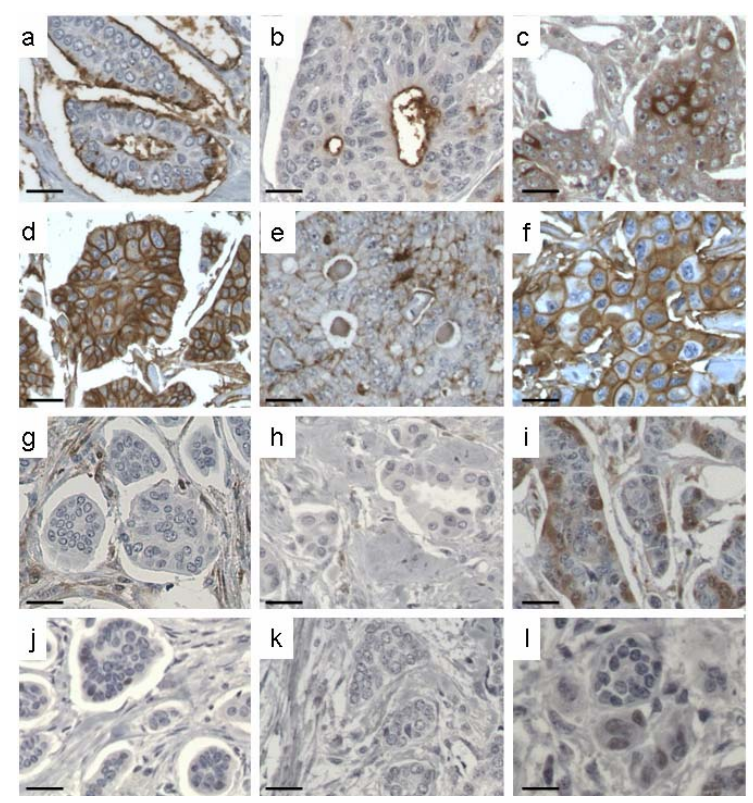

Figure 2. Examples of immunohistochemical staining for CD24, CD44, ALDH1 and EZH2 in breast carcinomas. Left panel: IMPC (a, d, g, j), middle panel: luminal A (b, e, h, k) and right panel: luminal B (c, f, i, l) IC-NST. Scale: $20 \mu \mathrm{m}$.

Table 2. CD24, CD44, ALDH1 and EZH2 expression patterns, based on immunohistochemical analyses, as a function of tumor subtype. 1) $p$-val IMPC vs luminal A IC-NST ; 2) $p$-val IMPC vs luminal B IC-NST; 3) p-val luminal A IC-NST vs luminal B IC-NST.

\begin{tabular}{|c|c|c|c|c|c|c|}
\hline & IMPC & Lum A & Lum B & 1 & 2 & 3 \\
\hline & & $\mathrm{n}(\%)$ & & & $p$-value & \\
\hline Number of patients & 28 & 27 & 34 & & & \\
\hline \multicolumn{7}{|l|}{ CD44 } \\
\hline Positive & $22(79)$ & $24(89)$ & $24(70)$ & & & \\
\hline membranous & $10(36)$ & $3(11)$ & $6(18)$ & & & \\
\hline membranocytoplasmic & $8(29)$ & $18(67)$ & $8(23)$ & $2.1 \times 10^{-2}$ & $\mathrm{~ns}$ & $1.3 \times 10^{-2}$ \\
\hline cytoplasmic & $4(14)$ & $3(11)$ & $10(29)$ & & & \\
\hline Not specified & $1(4)$ & $0(0)$ & $0(0)$ & & & \\
\hline \multicolumn{7}{|l|}{$\mathrm{CD} 24$} \\
\hline Positive & $27(96)$ & $20(74)$ & $30(88)$ & & & \\
\hline apical membranous & $23(85)$ & $9(45)$ & $4(13)$ & $6.8 \times 10^{-4}$ & $1.1 \times 10^{-7}$ & ns \\
\hline $\begin{array}{c}\text { circumferential } \\
\text { membranocytoplasmic }\end{array}$ & $4(15)$ & $11(55)$ & $26(87)$ & $5.7 \times 10^{-2}$ & $3.8 \times 10^{-6}$ & $1.0 \times 10^{-2}$ \\
\hline $\mathrm{CD}_{4} 4^{+} / \mathrm{CD} 24^{-}$ & $1(4)$ & $7(26)$ & $3(9)$ & & & \\
\hline $\mathrm{CD} 44^{+} / \mathrm{CD} 24^{+}$ & $21(75)$ & $18(67)$ & $21(62)$ & & & \\
\hline $\mathrm{CD} 44^{-} / \mathrm{CD} 24^{-}$ & $5(17)$ & $0(0)$ & $1(3)$ & $8.3 \times 10^{-3}$ & $7.3 \times 10^{-3}$ & $\mathrm{~ns}$ \\
\hline $\mathrm{CD} 44^{-} / \mathrm{CD} 24^{+}$ & $0(0)$ & $2(7)$ & $9(26)$ & & & \\
\hline Not specified & $1(4)$ & $0(0)$ & $0(0)$ & & & \\
\hline \multicolumn{7}{|l|}{ ALDH1 } \\
\hline Epithelial cells & $7(25)$ & $3(11)$ & $5(15)$ & $\mathrm{ns}$ & $\mathrm{ns}$ & $\mathrm{ns}$ \\
\hline Stroma & $25(89)$ & $14(52)$ & 27 (79) & $5.8 \times 10^{-3}$ & $\mathrm{~ns}$ & $4.5 \times 10^{-2}$ \\
\hline \multicolumn{7}{|l|}{ EZH2 } \\
\hline Positive & $1(4)$ & $0(0)$ & $12(35)$ & $\mathrm{ns}$ & $6.1 \times 10^{-3}$ & $6.1 \times 10^{-3}$ \\
\hline
\end{tabular}


ling was positive in $96 \%$ of IMPC (27/28 patients), $74 \%$ of luminal A (20/27 patients) and $88 \%$ of luminal B IC-NST cases (30/34 patients). Two different patterns of CD24 staining were observed, with labelling either only localized at the apical membrane or at the cytoplasmic membrane (circumferential staining). In most IMPC cases, CD24 staining was observed at the apical membrane (Figure 2(a)) [ $85 \%$ versus $45 \%$ of luminal A tumors $\left(\right.$ Figure 2(b)) $\left(p\right.$-val $\left.=6.8 \times 10^{-4}\right)$ or $13 \%$ of luminal B tumors $($ Figure 2(c) $)\left(p\right.$-val $\left.\left.=1.1 \times 10^{-7}\right)\right]$.

CD44 staining was detected in most tumors of all three types [79\% of IMPC (22/28 patients) (Figure 2(d)), 89\% of luminal A tumors (Figure 2(e)) (24/27 patients), and $70 \%$ of luminal B tumors (Figure 2(f)) (24/34 patients)]. However, the localization of this staining differed: both membranous and cytoplasmic in luminal A tumors, membranous in IMPC (36\% of cases) and cytoplasmic in luminal B tumors ( $29 \%$ of cases).

The coexistence of cells expressing CD44 and cells expressing CD24 within the same tumor was then analyzed. $\mathrm{CD} 44^{+}$and $\mathrm{CD} 24^{+}$cells were observed in most cases of the three subtypes studied (75\% of IMPC, $67 \%$ of luminal A tumors and $62 \%$ of luminal B tumors). However, the luminal A subgroup comprised the highest percentage of cases with $\mathrm{CD} 44^{+} / \mathrm{CD} 24^{-}$cells: $26 \%$, versus only $4 \%$ for IMPC cases. No significant difference was observed between luminal B tumors and IMPC in terms of the proportion of cases with $\mathrm{CD} 44^{+} / \mathrm{CD} 24^{-}$cells ( $9 \%$ versus $4 \% ; p$-val $=\mathrm{ns}$ ).

ALDH1 has been recognized as a putative marker of BrCICs. ALDH1 expression was therefore assessed in this series of cases. ALDH1 was expressed in only $25 \%$ of IMPC and $11 \%$ of luminal A and $15 \%$ of luminal B tumor cells per case. The proportion of $\mathrm{ALDH1}^{+}$cells was $90 \%$ in only one IMPC case, which was negative for both ER and PR. All but three IMPC cases presented $\mathrm{ALDH}^{+}{ }^{+}$stromal cells. ALDH1 was clearly expressed in the stroma in most cases of all three tumor types, but more frequently in IMPC $(25 / 28,89 \%)$ and luminal B $(27 / 34,79 \%)$ than in luminal A IC-NST $(14 / 27,52 \%)$ (Table 2; Figures 2(g)-(i)).

EZH2 has been identified as a marker of BrCICs and of breast carcinomas with poor prognosis. EZH2 expression was therefore evaluated in this series of IMPC and luminal A and B tumor controls. One of the 28 IMPC (4\%) displayed nuclear EZH2 expression, whereas no EZH2 expression was detected in any of the luminal A tumors (100\% negative). Twelve of the 34 cases of luminal B tumors displayed nuclear EZH2 expression (35\% cases), with $1 \%$ to $25 \%$ of cells positive for this marker in each case. EZH2 was more frequently expressed in luminal $\mathrm{B}$ tumors than in the other tumor types (luminal $\mathrm{B}$ versus IMPC, $p$-val $=6.1 \times 10^{-3}$; luminal $\mathrm{B}$ versus luminal A, $p$-val $\left.=6.1 \times 10^{-3}\right)($ Figures $2(\mathbf{j})-(\mathbf{l}))$. Notably, the EZH2 positive IMPC case was grade 2 whereas all grade 3 IMPC cases were EZH2 negative.

\subsection{Association with Outcome}

The definition of IMPC patients outcome remains controversial. Clinical data were available for all patients. We tried to assess the outcome of the three groups (IMPC, luminal A and B IC-NST) knowing the putative weaknesses of this evaluation (the retrospective nature of the study, the different periods of patient's clinical management, the different clinico-pathological characteristics among the groups). In addition, within the IMPC group, tumors were further classified as "luminal A IMPC" or "luminal B IMPC". This sub-classification allowed us to compare the specific outcome of these two groups of IMPC together and to that of luminal A and B IC-NST respectively.

At 10 years, IMPC patients had overall survival rates similar to those for patients with luminal A IDC tumors (Figure 3, upper left panel) ( $p$-val $=n s$; median followup of 84 [47 - 121] and 39 [2-108] months for IMPC and luminal A IDC, respectively) but significantly higher

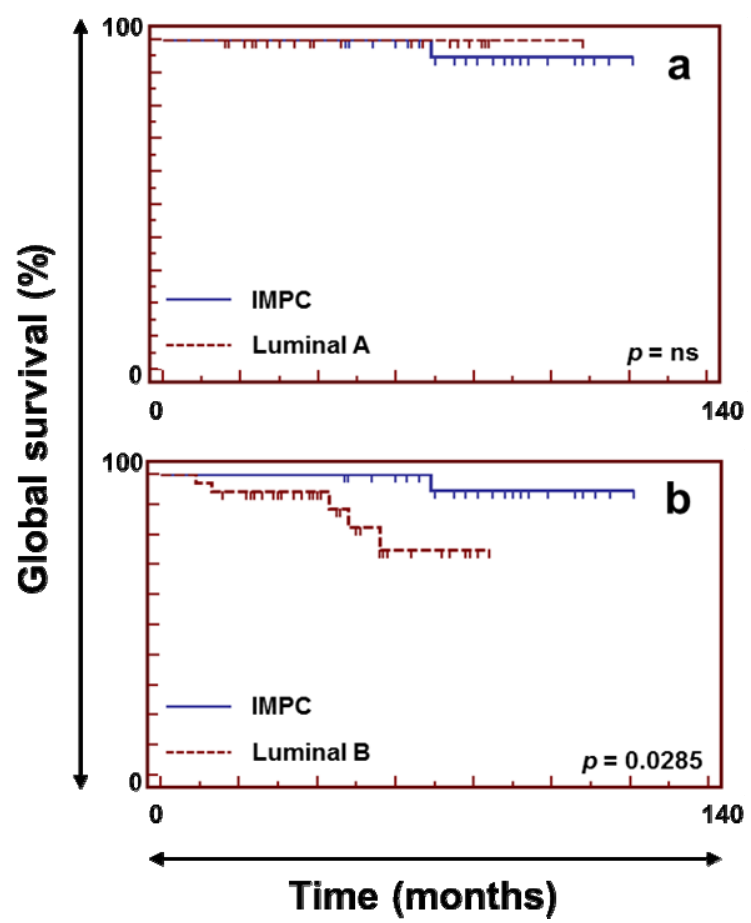

Figure 3. Survival curves for IMPC and luminal A and B invasive carcinomas not otherwise specified. The upper left panel (a) shows a comparison of overall survival between IMPC (solid line) and luminal A IC-NST (dashed line). The lower left panel (b) shows a comparison of overall survival between IMPC (solid line) and luminal B IC-NST (dashed line). 
overall survival rates than patients with luminal B IDC tumors (Figure 3, lower left panel) ( $p$-val $=2.8 \times 10^{-2}$; median follow-up of $42[9-84]$ months for luminal B IDC). IMPC patients had recurrence-free survival rates similar to those of patients with luminal A or luminal B IDC ( $p$-val $=n s$ - data not shown).

We then compared the outcome according to the molecular subgroups defined as described in material and methods. Luminal A and B IC-NST showed statistically significant different outcome ( $p$-val $=1.2 \times 10^{-2}(\mathrm{DFS})$; $p$-val $\left.=3.7 \times 10^{-2}(\mathrm{OS})\right)$. Luminal A and B IMPC experienced the same overall survival and disease-free survival $(p$-val $=n s)$. Luminal A IMPC and luminal A IC-NST also experienced the same outcome (OS and DFS, $p$-val $=$ ns). Identically, luminal B IMPC and luminal B IC-NST had also same overall and disease-free survival (Supplementary Figure 1).

\section{Discussion}

The various molecular subtypes of breast carcinomas and ductal carcinoma in situ (DCIS) have been shown to present patterns of so called "stem-cell related" marker expression different from those of IC-NST. Basal-like tumors have more $\mathrm{CD} 44^{+} / \mathrm{CD} 24^{-}$cells than luminal (A and B) and ERBB2 tumors [14]. EZH2 expression in breast carcinomas has been linked to poor prognosis [16]. We assessed the cellular pattern of expression of these markers (CD44, CD24, ALDH1 and EZH2) in IMPC and compared this pattern to that observed in luminal $\mathrm{A}$ and B IC-NST.

IMPC is a rare and unusual histological type, characterized by a very high rate of vascular and axillary lymph node invasion (about $60 \%$ to $70 \%$ of cases) and features of local and regional aggressiveness. IMPC have recently been shown to share phenotypic and genomic characteristics with luminal B carcinomas [21]. According to the proposed translation of molecular definitions of groups for clinical practice $[28,29]$, we classified the majority of IMPC cases as luminal B tumors, because most cases were positive for oestrogen receptors and had an Elston and Ellis histo-prognostic grade of II or III [30].

This study demonstrated that 1) IMPC differ from luminal B carcinomas by presenting a high level of membranous inverted apical CD24 expression; 2) EZH2 was much less frequently expressed in IMPC than in luminal B carcinomas; 3) IMPC patients had a favourable overall survival ( $85 \%$ at 10 years).

Different patterns of CD44 and CD24 expression have been reported for different tumor stages and molecular subtypes [14]. We observed quantitative differences in CD44 expression, which was weaker in IMPC than in luminal A tumors, and a qualitative difference in CD24 expression, which was detected at the inverted external apical pole of IMPC tumor cells and the apical pole of gland-forming cells in $45 \%$ of luminal $\mathrm{A}$ and $13 \%$ of luminal B tumors.

CD44 expression is associated with basal-like stem cells [14]. CD44 is more strongly expressed in DCIS than in invasive carcinomas, suggesting that the number of $\mathrm{CD}_{4} 4^{+}$cells may decrease with tumor progression. In our study, intense CD44 labelling was observed in all three tumor types studied. However, the distribution of this labelling differed between the tumor types: membranous and cytoplasmic in luminal A tumors, membranous in most IMPC and cytoplasmic in most luminal B tumors.

A shift in CD24 staining from the apical membrane to a membranous/cytoplasmic distribution during progression from DCIS to IC-NST has been reported [14]. We observed intense $\mathrm{CD} 24$ staining at the apical inverted poles of IMPC cells. This pattern has also been recently reported by other groups [31,32]. Although, the CD24 antibody used in our study, SN3b, and in these other studies, may recognize an unknown epitope different from the core CD24 protein, it has been proposed that CD24-positive cells might characterize epithelial cells differentiated into the luminal lineage [33]. IMPC should therefore be considered to be differentiated luminal tumors, in which the tumor cells are abnormally polarized, but in which polarization is still present. Conversely, in IC-NST, polarization is more frequently missing unless glandular differentiation is present. Recently, CD24 expression has been described as higher in cell lines derived from another tumor, well differentiated gastric carcinoma. Its expression at the apical membrane is a feature specific to IMPC that could therefore reflect the well differentiated nature of IMPC [34].

No staining for EZH2 was observed in the luminal A group and $\mathrm{EZH} 2$ expression levels were very low in IMPC ( $4 \%$ positive). The only IMPC case displaying EZH2 expression overexpressed ERBB2. In contrast, the frequency of EZH2 expression was significantly higher in luminal B tumors, which are known to have a poor prognosis.

IMPC tumors are associated with a high frequency of vascular and axillary lymph node invasion. Interestingly, in this series, eventhough the large majority of the IMPC cases was luminal, a small majority (54\% of the cases) were luminal B (ER+ and grade III or HER2 $3+$ ) but demonstrated an outcome identical to that of luminal A IMPC. These observations suggest that despite the high rates of axillary lymph node metastasis and vascular invasion, this outcome could be related either to the small tumors size being mostly $\mathrm{T} 1$ and $\mathrm{T} 2$ in this series or to IMPC histological type per se and its biological properties without excluding also the possibility of a high sen- 
sitivity to treatments. The ERBB2 overexpression pattern of IMPC has been reported to be unusual in that it is confined to three sides of the cells, excluding the apical inverted pole [35]. We and other authors [36] have reported low rates of HER2 amplification/overexpression in small $\mathrm{T} 1 \mathrm{a}, \mathrm{b}$ tumors ranging around $9 \%$ of the cases. In contrast, in this series of T1 and small T2 IMPC, a higher rate of HER2 overexpression is observed.

Paradoxically, $\mathrm{CD} 44^{+} / \mathrm{CD} 24^{-}$cells have been reported to be associated with greater invasiveness in an in vitro model [37]. However, IMPC tumors, which had vascular and axillary lymph node invasion rates of $70 \%$ in this series, displayed intense CD24 labelling of the apical inverted pole in most cases. Interestingly, CD24 is also a glycoprotein known to have a role in cell proliferation and that has been shown to be expressed in gastric carcinomas associated with lymph node metastasis and vascular invasion [34].

The percentage of ALDH1-positive tumors in the present study was lower than reported in other studies (7\% to $30 \% \mathrm{ALDH1}^{+}$tumors) $[8,15]$. However, ALDH1 staining within the stroma was observed in most cases in this study, even in the absence of epithelial staining. This observation challenges the use of ALDH1 as an epithelial stem cell-related marker, at least in this rare histological subtype. In luminal A and B IC-NST, ALDH1 staining patterns were consistent with the low frequency of cells positive for stem cell-related markers on immunohistochemistry. In previous studies based on cell sorting approaches, basal-like carcinomas were identified as the molecular group enriched in tumor-initiating cells/stem cells [33].

In conclusion, IMPC should be considered to be different from other luminal carcinomas, as CD24 is expressed at the inverted apical cellular pole associated with small numbers of $\mathrm{EHZ2}^{+}$and $\mathrm{ALDH1}^{+}$epithelial cells.

\section{Acknowledgements}

This work was supported by grants from INSERM and the Institut Curie (Programme Incitatif et Coopératif "Polarité et mitose"). Dr. Anne Vincent-Salomon was supported by an "Interface INSERM" grant.

\section{REFERENCES}

[1] C. M. Perou, T. Sorlie, M. B. Eisen, M. van de Rijn, S. S. Jeffrey, C. A. Rees, J. R. Pollack, D. T. Ross, H. Johnsen, L. A. Akslen, O. Fluge, A. Pergamenschikov, C. Williams, S. X. Zhu, P. E. Lonning, A. L. Borresen-Dale, P. O. Brown and D. Botstein, "Molecular Portraits of Human Breast Tumours," Nature, Vol. 406, No. 6797, 2000, pp. 747-752. doi:10.1038/35021093

[2] T. Sorlie, R. Tibshirani, J. Parker, T. Hastie, J. S. Marron, A. Nobel, S. Deng, H. Johnsen, R. Pesich, S. Geisler, J.
Demeter, C. M. Perou, P. E. Lonning, P. O. Brown, A.-L. Borresen-Dale and D. Botstein, "Repeated Observation of Breast Tumor Subtypes in Independent Gene Expression Data Sets," Proceedings of the National Academy of Sciences, Vol. 100, No. 14, 2003, pp. 8418-8423. doi:10.1073/pnas.0932692100

[3] P. Farmer, H. Bonnefoi, V. Becette, M. Tubiana-Hulin, P. Fumoleau, D. Larsimont, G. Macgrogan, J. Bergh, D. Cameron, D. Goldstein, S. Duss, A. L. Nicoulaz, C. Brisken, M. Fiche, M. Delorenzi and R. Iggo, "Identification of Molecular Apocrine Breast Tumours by Microarray Analysis," Oncogene, Vol. 24, No. 29, 2005, pp. 4660-4671. doi:10.1038/sj.onc. 1208561

[4] B. T. Hennessy, A. M. Gonzalez-Angulo, K. StemkeHale, M. Z. Gilcrease, S. Krishnamurthy, J. S. Lee, J. Fridlyand, A. Sahin, R. Agarwal, C. Joy, W. Liu, D. Stivers, K. Baggerly, M. Carey, A. Lluch, C. Monteagudo, X. He, V. Weigman, C. Fan, J. Palazzo, G. N. Hortobagyi, L. K. Nolden, N. J. Wang, V. Valero, J. W. Gray, C. M. Perou and G. B. Mills, "Characterization of a Naturally Occurring Breast Cancer Subset Enriched in Epithelial-toMesenchymal Transition and Stem Cell Characteristics," Cancer Research, Vol. 69, No. 10, 2009, pp. 4116-4124. doi:10.1158/0008-5472.CAN-08-3441

[5] E. Charafe-Jauffret, C. Ginestier, F. Iovino, C. Tarpin, M. Diebel, B. Esterni, G. Houvenaeghel, J. M. Extra, F. Bertucci, J. Jacquemier, L. Xerri, G. Dontu, G. Stassi, Y. Xiao, S. H. Barsky, D. Birnbaum, P. Viens and M. S. Wicha, "Aldehyde Dehydrogenase 1-Positive Cancer Stem Cells Mediate Metastasis and Poor Clinical Outcome in Inflammatory Breast Cancer," Clinical Cancer Research, Vol. 16, No. 1, 2009, pp. 45-55. doi:10.1158/1078-0432.CCR-09-1630

[6] K. Polyak and W. C. Hahn, "Roots and Stems: Stem Cells in Cancer," Nature Medicine, Vol. 12, No. 3, 2006, pp. 296-300. doi:10.1038/nm1379

[7] M. Al-Hajj, M. S. Wicha, A. Benito-Hernandez, S. J. Morrison and M. F. Clarke, "Prospective Identification of Tumorigenic Breast Cancer Cells," Proceedings of the National Academy of Sciences of the USA, Vol. 100, No. 7, 2003, pp. 3983-3988. doi:10.1073/pnas.0530291100

[8] C. Ginestier, M. H. Hur, E. Charafe-Jauffret, F. Monville, J. Dutcher, M. Brown, J. Jacquemier, P. Viens, C. G. Kleer, S. Liu, A. Schott, D. Hayes, D. Birnbaum, M. S. Wicha and G. Dontu, "ALDH1 Is a Marker of Normal and Malignant Human Mammary Stem Cells and a Predictor of Poor Clinical Outcome," Cell Stem Cell, Vol. 1, No. 5, 2007, pp. 555-567. doi:10.1016/j.stem.2007.08.014

[9] L. Ho and G. R. Crabtree, "An EZ Mark to Miss," Cell Stem Cell, Vol. 3, No. 6, 2008, pp. 577-578. doi:10.1016/i.stem.2008.11.007

[10] M. Zeidler and C. G. Kleer, "The Polycomb Group Protein Enhancer of Zeste 2: Its Links to DNA Repair and Breast Cancer," Journal of Molecular Histology, Vol. 37, No. 5-7, 2006, pp. 219-223. doi:10.1007/s10735-006-9042-9

[11] T. Tanei, K. Morimoto, K. Shimazu, S. J. Kim, Y. Tanji, T. Taguchi, Y. Tamaki and S. Noguchi, "Association of Breast Cancer Stem Cells Identified by Aldehyde Dehy- 
drogenase 1 Expression with Resistance to Sequential Paclitaxel and Epirubicin-Based Chemotherapy for Breast Cancers," Clinical Cancer Research, Vol. 15, No. 12, 2009, pp. 4234-4241.

doi:10.1158/1078-0432.CCR-08-1479

[12] M. H. Wright, A. M. Calcagno, C. D. Salcido, M. D. Carlson, S. V. Ambudkar and L. Varticovski, "Brcal Breast Tumors Contain Distinct CD44+/CD24- and CD133+ Cells with Cancer Stem Cell Characteristics," Breast Cancer Research, Vol. 10, No. 1, 2008, p. R10. doi:10.1186/bcr1855

[13] G. Honeth, P. O. Bendahl, M. Ringner, L. H. Saal, S. K. Gruvberger-Saal, K. Lovgren, D. Grabau, M. Ferno, A. Borg and C. Hegardt, "The CD44+/CD24-Phenotype Is Enriched in Basal-Like Breast Tumors," Breast Cancer Research, Vol. 10, No. 3, 2008, p. R53. doi: $10.1186 /$ bcr2108

[14] S. Y. Park, H. E. Lee, H. Li, M. Shipitsin, R. Gelman and K. Polyak, "Heterogeneity for Stem Cell-Related Markers According to Tumor Subtype and Histologic Stage in Breast Cancer," Clinical Cancer Research, Vol. 16, No. 3, 2010, pp. 876-887. doi:10.1158/1078-0432.CCR-09-1532

[15] V. Neumeister, S. Agarwal, J. Bordeaux, R. L. Camp and D. L. Rimm, "In Situ Identification of Putative Cancer Stem Cells by Multiplexing ALDH1, CD44, and Cytokeratin Identifies Breast Cancer Patients with Poor Prognosis," American Journal of Pathology, Vol. 176, No. 5, 2010, pp. 2131-2138. doi:10.2353/ajpath.2010.090712

[16] C. G. Kleer, Q. Cao, S. Varambally, R. Shen, I. Ota, S. A. Tomlins, D. Ghosh, R. G. Sewalt, A. P. Otte, D. F. Hayes, M. S. Sabel, D. Livant, S. J. Weiss, M. A. Rubin and A. M. Chinnaiyan, "EZH2 Is a Marker of Aggressive Breast Cancer and Promotes Neoplastic Transformation of Breast Epithelial Cells," Proceedings of the National Academy of Sciences of the USA, Vol. 100, No. 20, 2003, pp. 11606-11611. doi:10.1073/pnas. 1933744100

[17] B. Weigelt, F. C. Geyer and J. S. Reis-Filho, "Histological Types Of Breast Cancer: How Special Are They?" Molecular Oncology, Vol. 4, No. 3, 2010, pp. 192-208. doi:10.1016/i.molonc.2010.04.004

[18] F. F. de Beca, P. Caetano, R. Gerhard, C. A. Alvarenga, M. Gomes, J. Paredes and F. Schmitt, "Cancer Stem Cells Markers CD44, CD24 and ALDH1 in Breast Cancer Special Histological Types," Journal of Clinical Pathology, Vol. 66, No. 3, 2012, pp. 187-191.

[19] O. Zekioglu, Y. Erhan, M. Ciris, H. Bayramoglu and N. Ozdemir, "Invasive Micropapillary Carcinoma of the Breast: High Incidence of Lymph Node Metastasis with Extranodal Extension and Its Immunohistochemical Profile Compared with Invasive Ductal Carcinoma," Histopathology, Vol. 44, No. 1, 2004, pp. 18-23. doi:10.1111/j.1365-2559.2004.01757.x

[20] B. Weigelt, H. M. Horlings, B. Kreike, M. M. Hayes, M. Hauptmann, L. F. Wessels, D. de Jong, M. J. Van de Vijver, L. J. Van't Veer and J. L. Peterse, "Refinement of Breast Cancer Classification by Molecular Characterization of Histological Special Types," Journal of Pathology, Vol. 216, No. 2, 2008, pp. 141-150.

doi:10.1002/path. 2407
[21] C. Marchio, M. Iravani, R. Natrajan, M. B. Lambros, K. Savage, N. Tamber, K. Fenwick, A. Mackay, R. Senetta, S. Di Palma, F. C. Schmitt, G. Bussolati, L. O. Ellis, A. Ashworth, A. Sapino and J. S. Reis-Filho, "Genomic and Immunophenotypical Characterization of Pure Micropapillary Carcinomas of the Breast," Journal of Pathology, Vol. 215, No. 4, 2008, pp. 398-410.

[22] B. Haibe-Kains, C. Desmedt, S. Loi, A. C. Culhane, G. Bontempi, J. Quackenbush and C. Sotiriou, "A ThreeGene Model to Robustly Identify Breast Cancer Molecular Subtypes," Journal of the National Cancer Institute, Vol. 104, No. 4, 2012, pp. 311-325. doi:10.1093/jnci/djr545

[23] B. Zafrani, M. H. Aubriot, E. Mouret, P. De Cremoux, Y. De Rycke, A. Nicolas, E. Boudou, A. Vincent-Salomon, H. Magdelenat and X. Sastre-Garau, "High Sensitivity and Specificity of Immunohistochemistry for the Detection of Hormone Receptors in Breast Carcinoma: Comparison with Biochemical Determination in a Prospective Study of 793 Cases," Histopathology, Vol. 37, No. 6, 2000, pp. 536-545. doi:10.1046/j.1365-2559.2000.01006.x

[24] A. C. Wolff, M. E. Hammond, J. N. Schwartz, K. L. Hagerty, D. C. Allred, R. J. Cote, M. Dowsett, P. L. Fitzgibbons, W. M. Hanna, A. Langer, L. M. McShane, S. Paik, M. D. Pegram, E. A. Perez, M. F. Press, A. Rhodes, C. Sturgeon, S. E. Taube, R. Tubbs, G. H. Vance, M. van de Vijver, T. M. Wheeler and D. F. Hayes, "American Society of Clinical Oncology/College of American Pathologists Guideline Recommendations for Human Epidermal Growth Factor Receptor 2 Testing in Breast Cancer," Archives of Pathology \& Laboratory Medicine, Vol. 131, No. 1, 2007, p. 18.

[25] S. Ricardo, A. F. Vieira, R. Gerhard, D. Leitao, R. Pinto, J. F. Cameselle-Teijeiro, F. Milanezi, F. Schmitt and J. Paredes, "Breast Cancer Stem Cell Markers CD44, CD24 and ALDH1: Expression Distribution within Intrinsic Molecular Subtype," Journal of Clinical Pathology, Vol. 64, No. 11, 2011, pp. 937-946. doi:10.1136/jep.2011.090456

[26] R. Gerhard, S. Ricardo, A. Albergaria, M. Gomes, A. R. Silva, A. F. Logullo, J. F. Cameselle-Teijeiro, J. Paredes and F. Schmitt, "Immunohistochemical Features of Claudin-Low Intrinsic Subtype in Metaplastic Breast Carcinomas," Breast, Vol. 21, No. 3, 2012, pp. 354-360. doi:10.1016/j.breast.2012.03.001

[27] L. P. Kunju, C. Cookingham, K. A. Toy, W. Chen, M. S. Sabel and C. G. Kleer, "EZH2 and ALDH-1 Mark Breast Epithelium at Risk for Breast Cancer Development," Modern Pathology, Vol. 24, No. 6, 2011, pp. 786-793. doi: $10.1038 /$ modpathol.2011.8

[28] M. C. U. Cheang, D. Voduc, C. Bajdik, S. Leung, S. McKinney, S. K. Chia, C. M. Perou and T. O. Nielsen, "Basal-Like Breast Cancer Defined by Five Biomarkers Has Superior Prognostic Value than Triple-Negative Phenotype," Clinical Cancer Research, Vol. 14, No. 5, 2008, pp. 1368-1376. doi:10.1158/1078-0432.CCR-07-1658

[29] T. O. Nielsen, F. D. Hsu, K. Jensen, M. Cheang, G. Karaca, Z. Hu, T. Hernandez-Boussard, C. Livasy, D. Cowan, 
L. Dressler, L. A. Akslen, J. Ragaz, A. M. Gown, C. B. Gilks, M. van de Rijn and C. M. Perou, "Immunohistochemical and Clinical Characterization of the Basal-Like Subtype of Invasive Breast Carcinoma," Clinical Cancer Research, Vol. 10, No. 16, 2004, pp. 5367-5374. doi:10.1158/1078-0432.CCR-04-0220

[30] J. S. Parker, M. Mullins, M. C. Cheang, S. Leung, D. Voduc, T. Vickery, S. Davies, C. Fauron, X. He, Z. Hu, J. F. Quackenbush, I. J. Stijleman, J. Palazzo, J. S. Marron, A. B. Nobel, E. Mardis, T. O. Nielsen, M. J. Ellis, C. M. Perou and P. S. Bernard, "Supervised Risk Predictor of Breast Cancer Based on Intrinsic Subtypes," Journal of Clinical Oncology, Vol. 27, No. 8, 2009, pp. 1160-1167. doi:10.1200/JCO.2008.18.1370

[31] W. Li, F. Liu, T. Lei, X. Xu, B. Liu, L. Cui, J. Wei, X. Guo, R. Lang, Y. Fan, F. Gu, P. Tang, X. Zhang and L. $\mathrm{Fu}$, "The Clinicopathological Significance of $\mathrm{CD}_{4} 4^{+}$/ CD24 /Low and CD24 $4^{+}$Tumor Cells in Invasive Micropapillary Carcinoma of the Breast," Pathology: Research and Practice, Vol. 206, No. 12, 2010, pp. 828-834. doi:10.1016/j.prp.2010.09.008

[32] S. Simonetti, L. Terracciano, I. Zlobec, E. Kilic, L. Stasio, M. Quarto, G. Pettinato and L. Insabato, "Immunophenotyping Analysis in Invasive Micropapillary Carcinoma of the Breast: Role of CD24 and CD44 Isoforms Expression," Breast, Vol. 21, No. 2, 2012, pp. 165-170. doi:10.1016/j.breast.2011.09.004

[33] M. Shipitsin, L. L. Campbell, P. Argani, S. Weremowicz, N. Bloushtain-Qimron, J. Yao, T. Nikolskaya, T. Serebryiskaya, R. Beroukhim, M. Hu, M. K. Halushka, S.
Sukumar, L. M. Parker, K. S. Anderson, L. N. Harris, J. E. Garber, A. L. Richardson, S. J. Schnitt, Y. Nikolsky, R. S. Gelman and K. Polyak, "Molecular Definition of Breast Tumor Heterogeneity," Cancer Cell, Vol. 11, No. 3, 2007, pp. 259-273. doi:10.1016/j.ccr.2007.01.013

[34] M. Takahashi, M. Nakajima, H. Ogata, Y. Domeki, K. Ohtsuka, K. Ihara, E. Kurayama, S. Yamaguchi, K. Sasaki, K. Miyachi and H. Kato, "CD24 Expression Is Associated with Progression of Gastric Cancer," Hepatogastroenterology, Vol. 60, No. 124, 2012, in press.

[35] A. Ranade, R. Batra, G. Sandhu, R. A. Chitale and J. Balderacchi, "Clinicopathological Evaluation of 100 Cases of Mucinous Carcinoma of Breast with Emphasis on Axillary Staging and Special Reference to a Micropapillary Pattern," Journal of Clinical Pathology, Vol. 63, No. 12, 2010, pp. 1043-1047. doi:10.1136/jcp.2010.082495

[36] M. J. Rodrigues, J. Wassermann, L. Albiges, E. Brain, S. Delaloge, D. Stevens, J. M. Guinebretiere, M. C. Mathieu, Y. Kirova, E. Guillot, A. Vincent-Salomon and P. H. Cottu, "Trastuzumab Treatment in T1ab, Node-Negative, Human Epidermal Growth Factor Receptor 2-Overexpressing Breast Carcinomas," Journal of Clinical Oncology, Vol. 28, No. 28, 2010, pp. e541-e542. doi:10.1200/JCO.2010.29.7952

[37] M. J. Meyer, J. M. Fleming, M. A. Ali, M. W. Pesesky, E. Ginsburg and B. K. Vonderhaar, "Dynamic Regulation of CD24 and the Invasive, CD44posCD24neg Phenotype in Breast Cancer Cell Lines," Breast Cancer Research, Vol. 11, No. 6, 2009, p. R82. doi:10.1186/bcr2449 


\section{Supplementary Figure}
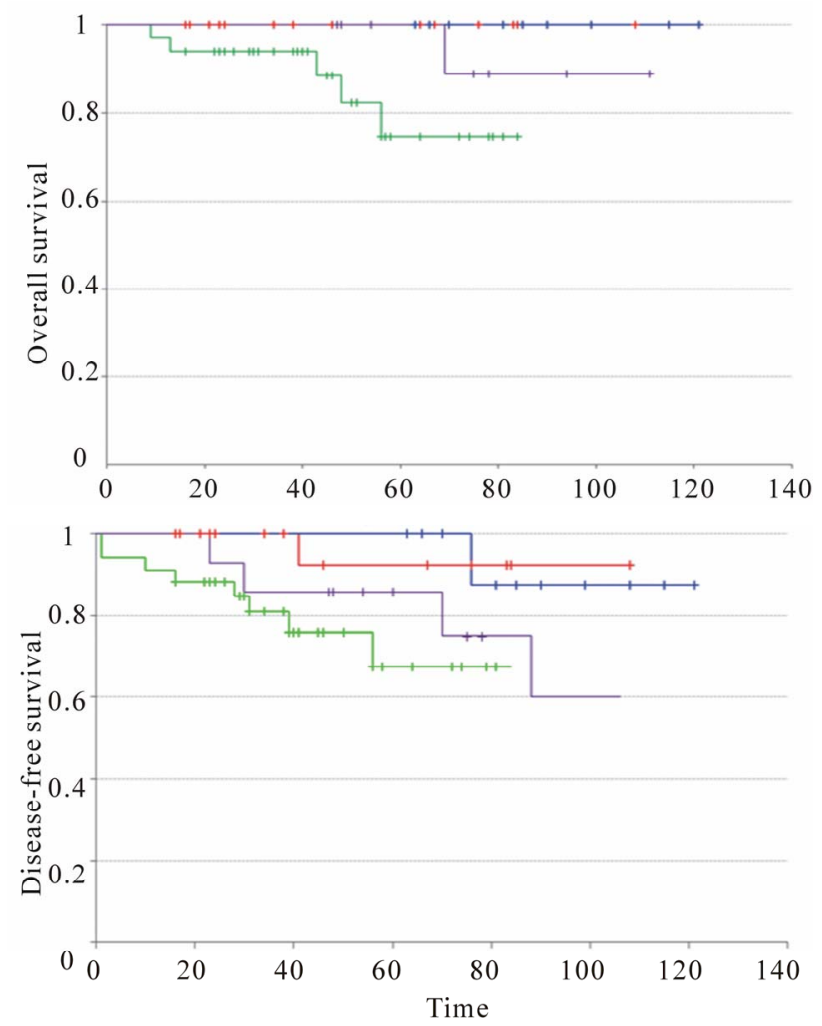

Figure 1. Overall and disease-free survival curves Luminal $A$ and Luminal B IMPC and for luminal $A$ and luminal $B$ IC-NST. The upper panel shows a comparison of overall survival between luminal A IMPC (blue line), luminal B IMPC (purple line), luminal A IC-NST (red line) and luminal B IC-NST (green line). The lower panel shows a comparison of disease free-survival between luminal $A$ IMPC (blue line), luminal B IMPC (purple line), luminal A IC-NST (red line) and luminal B IC-NST (green line). 